\title{
PENGARUH MODEL PEMBELAJARAN KOOPERATIF TIPE KOSAJI TERHADAP ASPEK KOGNITIF FISIKA PESERTA DIDIK
}

\author{
Rumansyah1, Kurniawan Arizona ${ }^{2 *}$ \\ 1SMAN 1 Mataram, Jl. Pendidikan No. 21 Mataram, Indonesia \\ ${ }^{2}$ Tadris Fisika, Fakultas Tarbiyah dan Keguruan, Universitas Islam Negeri Mataram, \\ Mataram, Indonesia. \\ E-mail: arizona@uinmataram.ac.id
}

\begin{abstract}
ABSTRAK
Aspek kognitif merupakan ranah yang paling disoroti oleh pendidik. Perlu adanya model pembelajaran yang tepat untuk mengantarkan peserta didik meraih hasil belajar kognitif yang tinggi. Salah satu model pembelajaran yang memfasilitasi peserta didik untuk meraih aspek kognitif yang baik adalah model pembelajaran koopertaif tipe KOSAJI. Riset ini bertujuan untuk menganalisis pengaruh model pembelajaran kooperatif tipe KOSAJI terhadap hasil belajar kognitif. Jenis penelitian yang digunakan eksperimen semu dengan desain pretest posttest group design. Populasi penelitian adalah 260 peserta didik kelas X salah satu sekolah di Kota Mataram yang tersebar pada 7 kelas. Sampel penelitian berjumlah 116 peserta didik, terbagi menjadi 3 kelas dengan teknik pengambilan cluster random sampling. Instrumen penelitian berupa tes hasil belajar kognitif yang diberikan pada awal dan akhir penelitian. Data hasil penelitian dianalisis dengan Anava satu jalur dilanjutkan dengan uji Tukey HSD untuk melihat model pembelajaran yang memiliki pengaruh paling nyata. Hasil penelitian menunjukkan bahwa: model pembelajaran kooperatif tipe KOSAJI berpengaruh terhadap aspek kognitif fisika peserta didik. Sehingga penerapan model pembelajaran kooperatif tipe KOSAJI dapat menjadi alternatif dalam memfasilitasi peserta didik dalam meningkatkan aspek kognitif dalam pembelajaran fisika.
\end{abstract}

Kata kunci: model pembelajaran KOSAJI, aspek kognitif

\begin{abstract}
The cognitive aspect is the area most highlighted by educators. There is a need for an appropriate learning model to deliver students to achieve high cognitive learning outcomes. One of the learning models that facilitate students to achieve good cognitive aspects is the KOSAJI type of cooperative learning model. This research aims to analyze the effect of the cooperative learning model KOSAJI type on cognitive learning outcomes. This type of research used quasi-experimental design with pretest posttest group design. The study population was 260 students of class $X$ one of the schools in the city of Mataram spread over 7 classes. The research sample was 116 students, divided into 3 classes using cluster random sampling technique. The research instrument was a cognitive learning outcome test given at the beginning and end of the study. The research data were analyzed using one-way ANOVA followed by the Tukey HSD test to see which learning model has the most significant effect. The results showed that: the cooperative learning model KOSAJI type affects the cognitive aspects of students' physics. So that the application of cooperative learning model type KOSAJI can be an alternative in facilitating learners in improving cognitive aspects in physics learning.
\end{abstract}

Keywords: KOSAJI learning model, cognitive aspects

DOI: http://dx.doi.org/10.15575/jotalp.v6i1.10480

Received: 9 Desember 2021 ; Accepted: 16 Februari 2021 ; Published: 28 Februari 2021 


\section{PENDAHULUAN}

Salah satu problem pendidikan di Indonesia adalah kualitas yang masih rendah khususnya pada jenjang pendidikan menengah. Pada tingkat sekola menengah atas, mata pelajaran fisika dipandang penting untuk dipelajari oleh peserta didik dengan berbagai pertimbangan. Pertama, selain memberikan bekal ilmu kepada peserta didik, mata pelajaran fisika sebagai wadah dan sarana untuk menumbuhkan kemampuan berpikir kritis maupun kreatif yang berguna untuk memecahkan masalah di dalam kehidupan sehari-hari. Kedua, mata pelajaran fisika perlu diajarkan untuk tujuan yang lebih khusus yaitu membekali pengetahuan dan pemahaman dan sejumlah kemampuan yang dipersyaratkan peserta didik untuk memasuki jenjang yang lebih tinggi serta mengembangkan ilmu dan teknologi (Rumansyah, dkk., 2016).

Faktanya pembelajaran Fisika di tingkat SMA masih belum optimal. Nilai peserta didik pada mata pelajaran fisika di SMA tergolong belum maksimal, khususnya di salah satu sekolah di Kota Mataram. Hasil temuan awal yang peneliti peroleh di sekolah tersebut menunjukkan hasil ulangan harian materi suhu, kalor dan perpindahan kalor masih tergolong rendah. Hal ini disebabkan ada beberapa peserta didik memiliki nilai di bawah Kriteria Ketuntansan Minimal (KKM) yang telah ditentukan. Di samping itu beberapa kelas ketuntasan klasikalnya di bawah 85\%. Sebaran nilai ulangan harian suhu, kalor dan perpindahan kalor kelas X pada setiap kelas dapat dilihat pada Tabel 1.

Salah satu usaha untuk memperbaiki dan meningkatkan hasil belajar khusus pada aspek kognitif peserta didik pada mata pelajaran fisika adalah dengan melakukan inovasi dan perbaikan dalam proses pembelajaran fisika. Upaya dalam proses pembelajaran dapat dilakukan dengan mengimplementasikan model pembelajaran yang tepat. Hal ini bertujuan agar proses pembelajaran lebih terarah dan terukur. Salah satu alternatif model pembelajaran yang tepat dengan mata pelajaran fisika adalah model pembelajaran kooperatif, yang sesuai dengan pendekatan konstruktivisme. Pendekatan konstruktivisme yang dimaksud memfasilitasi peserta didik secara aktif membangun pengetahuan mereka sendiri dalam proses pembelajaran. Peran guru adalah membantu peserta didik menemukan fakta, konsep, prinsip, bahkan teori bagi diri mereka sendiri, bukan hanya memberikan ceramah atau mengendalikan seluruh kegiatan kelas (Nur dan Wikandari, 2000). Menurut pandangan teori motivasi, struktur tujuan kooperatif adalah menciptakan suatu situasi sedemikian rupa sehingga keberhasilan salah satu anggota kelas diakibatkan keberhasilan kelas itu sendiri. Oleh karena itu, untuk mencapai tujuan dari salah satu anggota, maka salah seorang anggota tersebut harus membantu teman kelasnya dengan melakukan apa saja yang dapat membantu kelas itu berhasil (Slavin, 2011).

Tabel 1. Hasil Penilaian Harian Materi Suhu dan Kalor Kelas X di Salah Satu Kota Mataram

\begin{tabular}{cccccc}
\hline No. Kelas & $\begin{array}{c}\text { Jumlah } \\
\text { Peserta } \\
\text { didik }\end{array}$ & $\begin{array}{c}\text { Rata- } \\
\text { rata }\end{array}$ & KKM & $\begin{array}{c}\text { Ketuntasan } \\
\text { (\%) }\end{array}$ \\
\hline 1. & $\mathrm{X}_{1}$ & 38 & 86,5 & 75 & 87,0 \\
\hline $\mathbf{2 .}$ & $\mathrm{X}_{2}$ & 38 & 84,0 & 75 & 83,2 \\
\hline $\mathbf{3 .}$ & $\mathrm{X}_{3}$ & 38 & 77,2 & 75 & 75,6 \\
\hline $\mathbf{4 .}$ & $\mathrm{X}_{4}$ & 38 & 78,1 & 75 & 76,5 \\
\hline $\mathbf{5 .}$ & $\mathrm{X}_{5}$ & 39 & 80,5 & 75 & 77,8 \\
\hline $\mathbf{6 .}$ & $\mathrm{X}_{6}$ & 38 & 82,1 & 75 & 78,5 \\
\hline
\end{tabular}

(Sumber: Dokumen Guru Matapelajaran Fisika)

Pembelajaran secara kooperatif memberikan pandangan bahwa manusia belajar dari pengalaman mereka dan berpartisipasi aktif dalam kelompok kecil membantu peserta didik belajar keterampilan sosial yang penting. Selain itu juga secara bersamaan dapat mengembangkan sikap demokratis dan keterampilan berpikir logis. Model pembelajaran kooperatif dapat memperbaiki dan meningkatkan kemampuan kognitif peserta didik terhadap mata pelajaran (Ibrahim dkk., 2000). Banyak model pembelajaran koopertif yang diterapkan selama ini. Model pembelajaran kooperatif yang cukup mudah untuk diimplementasikan di kelas di antaranya tipe Students Team Achievement Division (STAD) dan Jigsaw. 
Tabel 2. Perbandingan Kooperatif Tipe STAD dan Jigsaw

\begin{tabular}{|c|c|c|}
\hline & STAD & Jigsaw \\
\hline $\begin{array}{l}\text { Tujuan } \\
\text { kognitif }\end{array}$ & $\begin{array}{l}\text { Informasi } \\
\text { akademik } \\
\text { sederhana }\end{array}$ & $\begin{array}{l}\text { Informasi } \\
\text { akademik } \\
\text { sederhana }\end{array}$ \\
\hline $\begin{array}{l}\text { Tujuan } \\
\text { sosial }\end{array}$ & $\begin{array}{l}\text { Kerja kelompok } \\
\text { dan kerjasama }\end{array}$ & $\begin{array}{l}\text { Kerja kelompok } \\
\text { dan kerjasama }\end{array}$ \\
\hline Struktur tim & $\begin{array}{l}\text { Kelompok belajar } \\
\text { heterogen } \\
\text { dengan } 4-5 \text { orang } \\
\text { anggota }\end{array}$ & $\begin{array}{l}\text { Kelompok } \\
\text { belajar } \\
\text { heterogen } \\
\text { dengan 5-6 } \\
\text { orang anggota } \\
\text { menggunakan } \\
\text { pola kelompok } \\
\text { "asal" dan } \\
\text { kelompok "ahli" }\end{array}$ \\
\hline $\begin{array}{l}\text { Pemilihan } \\
\text { topik } \\
\text { pelajaran } \\
\end{array}$ & Biasanya guru & Biasanya guru \\
\hline $\begin{array}{l}\text { Tugas } \\
\text { utama }\end{array}$ & $\begin{array}{l}\text { Peserta didik } \\
\text { dapat } \\
\text { menggunakan } \\
\text { lembar kegiatan } \\
\text { peserta didik dan } \\
\text { saling membantu } \\
\text { untuk } \\
\text { menuntaskan } \\
\text { materi belajarnya }\end{array}$ & $\begin{array}{l}\text { Peserta didik } \\
\text { mempelajari } \\
\text { materi dalam } \\
\text { kelompok "ahli" } \\
\text { kemudian } \\
\text { membantu } \\
\text { anggota } \\
\text { kelompok asal } \\
\text { mempelajari } \\
\text { materi itu }\end{array}$ \\
\hline Penilaian & Tes mingguan & $\begin{array}{l}\text { Bervariasi, } \\
\text { dapat berupa } \\
\text { tes mingguan }\end{array}$ \\
\hline Pengakuan & $\begin{array}{l}\text { Lembar } \\
\text { pengetahuan dan } \\
\text { publikasi lain }\end{array}$ & Publikasi lain \\
\hline
\end{tabular}

(Sumber: Ibrahim dkk., 2000)

Model pembelajaran kooperatif tipe STAD dan Jigsaw memiliki cirik has yang tidak jauh berbeda. Kedua model pembelajaran ini cukup sederhana namun memiliki potensi dalam mendukung berlangsungnya belajar aktif, inovatif, kreatif, efektif dan menyenangkan (PAIKEM). Adanya pemberian penghargaan kepada kelompok terbaik pada tipe STAD dan Jigsaw diasumsikan dapat menumbuhkan suasana menyenangkan bagi peserta didik (Sanjaya, 2011). Berikut rangkuman komparasi kedua model pembelajaran tersebut (STAD dan Jigsaw).
Tabel 3. Sintaks Pembelajaran Kooperatif Tipe KOSAJI

\begin{tabular}{|c|c|}
\hline Sintaks & Kegiatan \\
\hline Pembagian & Guru membentuk beberapa \\
\hline Kelompok & $\begin{array}{l}\text { kelompok (kelompok asal) } \\
\text { yang terdiri dari } 4 \text { atau } 6 \\
\text { peserta didik yang heterogen } \\
\text { dari latar belakang jenis } \\
\text { kelamin, etnis/suku, dan } \\
\text { kemampuan akademik. }\end{array}$ \\
\hline Presentasi Guru & $\begin{array}{l}\text { Guru membuat topik materi } \\
\text { pelajaran dan menjelaskan } \\
\text { tentang kemampuan yang } \\
\text { diharapkan dikuasai oleh } \\
\text { peserta didik } \\
\text { pembelajaran). }\end{array}$ \\
\hline $\begin{array}{l}\text { Menunjuk ahli } \\
\text { atau pakar }\end{array}$ & $\begin{array}{l}\text { Setiap peserta didik dari } \\
\text { kelompok asal diambil untuk } \\
\text { menjadi peserta didik dalam } \\
\text { kelompok ahli dan diberikan } \\
\text { komponen topic }\end{array}$ \\
\hline $\begin{array}{l}\text { Mengumpulkan } \\
\text { informasi dan } \\
\text { rapat ahli }\end{array}$ & $\begin{array}{l}\text { Peserta didik dalam kelompok } \\
\text { ahli mempelajari komponen } \\
\text { topik secara mendalam dan } \\
\text { menyiapkan presentasi yang } \\
\text { akan mereka sajikan kepada } \\
\text { kelompok asal. }\end{array}$ \\
\hline $\begin{array}{l}\text { Kegiatan belajar } \\
\text { dan review }\end{array}$ & $\begin{array}{l}\text { Setiap ahli mempresentasikan } \\
\text { topik yang sudah dikuasai } \\
\text { kepada kelompok asal dan } \\
\text { peserta didik meringkas semua } \\
\text { topik yang dipelajari serta } \\
\text { mengerjakan LKS yang sudah } \\
\text { dibagikan. }\end{array}$ \\
\hline Evaluasi & $\begin{array}{l}\text { Guru memberikan tes atau kuis } \\
\text { kepada peserta didik secara } \\
\text { individu dan tidak dibenarkan } \\
\text { bekerjasama. Hal ini dilakukan } \\
\text { untuk menjamin agar peserta } \\
\text { didik secara individu } \\
\text { bertanggung jawab kepada diri } \\
\text { sendiri dan memahami bahan } \\
\text { ajar. }\end{array}$ \\
\hline $\begin{array}{l}\text { Pemberian } \\
\text { Penghargaan }\end{array}$ & $\begin{array}{l}\text { Guru memberi penghargaan } \\
\text { berupa sertifikat atau bentuk } \\
\text { penghargaan lainnya kepada } \\
\text { peserta didik atau kelompok } \\
\text { peserta didik yang berhasil } \\
\text { mencapai kriteria yang sudah } \\
\text { ditentukan oleh guru. }\end{array}$ \\
\hline
\end{tabular}

(Sumber: Rumansyah, 2016)

Penelitian ini mencoba memadukan atau mengintegrasikan dua model pembelajaran kooperatif yaitu tipe STAD dan Jigsaw 
sehingga menghasilkan sebuah perpaduan model pembelajaran kooperatif tipe KOSAJI. Sintaks model pembelajaran kooperatif tipe KOSAJI hasil kombinasi yang dapat diterapkan tersaji pada Tabel 3 .

Pada era ini perlu suatu pendekatan atau model pembelajaran yang tepat untuk memfasilitasi peserta didik dalam menjawab tantangan hidup yang begitu dinamis. Daya kreasi dan inovasi peserta didik perlu dibina mulai sekarang agar memiliki kompetensi yang mumpuni untuk tetap eksis di tengah semakin sulitnya lapangan pekerjaan dan mendapatkan pekerjaan yang layak. Ke depan tidak lagi terpikir untuk mencari kerja, namun pekerjaan apa yang akan diciptakan. Inilah yang menjadi spirit seorang pendidik (guru) dalam menerapkan model pembelajaran yang tepat (Arizona, 2020). Salah satunya adalah model pembelajaran kooperatif tipe KOSAJI yang menitikberatkan kolaboratif setiap peserta didik untuk mencapai hasil belajar terutama pada aspek kognitif.

Hasil belajar dapat muncul dalam berbagai jenis perubahan tingkah laku seseorang, tentunya ke arah yang lebih baik (Sudjana, 2012). Selanjutnya menurut Slameto (2006) menyatakan bahwa hasil belajar adalah suatu proses usaha yang dilakukan seseorang untuk memperoleh suatu perubahan tingkah laku baru secara komprehensif sebagai hasil pengalamannya sendiri.

Hasil belajar tampak sebagai terjadinya perubahan tingkah laku pada diri peserta didik, yang dapat diamati dan diukur dalam bentuk perubahan pengetahuan, sikap dan keterampilan. Perubahan tersebut dapat diartikan terjadinya peningkatan dan pengembangan yang lebih baik dibandingkan dengan sebelumnya, misalnya dari tidak tahu menjadi tahu (Hamalik, 2004). Hasil belajar yang dicapai oleh peserta didik sangat erat kaitannya dengan rumusan tujuan pembelajaran yang direncanakan guru sebelumnya (Usman, 2005).

Hasil belajar adalah pola-pola perbuatan, nilainilai, pengertian-pengertian, sikap-sikap, apresiasi, dan keterampilan (Suprijono, 2012). Beberapa faktor yang mempengaruhi keberhasilan belajar yaitu faktor internal dan faktor eksternal. Faktor internal meliputi faktor biologis atau jasmaniah dan faktor psikologis. Faktor eksternal melitputi faktor lingkungan keluarga, sekolah, dan masyarakat (Slameto, 2006) .

Rumusan tujuan pendidikan berdasarkan sistem pendidikan nasional dikelompokkan menjadi tujuan kurikuler dan tujuan instruksional. Kedua tujuan ini menggunakan klasifikasi hasil belajar yang berpijak pada taksonomi Bloom. Secara garis besar taksonomi Bloom dibagi menjadi tiga domain: (a) domain kemampuan berpikir (kognitif), (b) domain berkenaan dengan sikap (afektif), dan (c) domain berkenaan dengan keterampilan (psikomotorik). Pada penelitian ini hasil belajar yang ingin diteliti terbatas pada domain kognitif. Ada enam kategori hasil belajar kognitif menurut taksonomi Bloom yang sudah direvisi yaitu kemampuan mengingat (C1), memahami (C2), menerapkan (C3), menganalisis (C4), mengevaluasi (C5), dan mengkreasi (C6) (Anderson \& Krathwohl, 2011).

Hasil belajar yang diidentifikasi dalam tulisan ini mengacu pada ranah kognitif, sehingga hasil belajar adalah tingkat penguasaan yang dicapai oleh peserta didik dalam mengikuti kegiatan belajar mengajar, sesuai dengan tujuan pembelajaran yang telah ditetapkan. Hubungannya dalam satuan pelajaran, ranah kognitif memegang peranan penting dan paling banyak disoroti. Sesuai yang diungkapkan Daryanto (2001) tujuan pengajaran pada umumnya adalah peningkatan kemampuan peserta didik dalam aspek kognitif.

Berdasarkan uraian tersebut, tujuan dari riset ini yaitu untuk menganalisis pengaruh model pembelajaran kooperatif tipe KOSAJI terhadap hasil belajar kognitif. Model pembelajaran kooperatif tipe KOSAJI dibandingkan dengan model pembelajaran kooperatif tipe STAD dan Jigsaw. Sehingga dapat dianalisis model pembelajaran kooperatif yang memiliki 
perbedaan paling nyata dari ketiga tipe model pembelajaran tersebut.

\section{METODE PENELITIAN}

Penelitian ini tergolong kuasi eksperimen (Sukmadinata, 2011). Rancangan penelitian yang digunakan yaitu rancangan PretestPosttest Group Design. Berdasarkan rancangan penelitian tersebut, prosedur eksperimen untuk penelitian ini terangkum pada Tabel 4.

Tabel 4. Prosedur Pelaksanaan Penelitian

\begin{tabular}{cccc}
\hline $\mathrm{R}$ & $\mathrm{T}_{1}$ & $\mathrm{x}_{1}$ & $\mathrm{~T}_{2}$ \\
\hline $\mathrm{R}$ & $\mathrm{T}_{1}$ & $\mathrm{x}_{2}$ & $\mathrm{~T}_{2}$ \\
\hline $\mathrm{R}$ & $\mathrm{T}_{1}$ & $\mathrm{x}_{3}$ & $\mathrm{~T}_{2}$ \\
\hline
\end{tabular}

\section{Keterangan:}

$\mathrm{R}=$ random; $\mathrm{T} 1$ = nilai pretes; $\mathrm{T} 2$ = nilai postes $\mathrm{x} 1$ = KOSAJI; $\mathrm{x} 2$ = STAD; $\mathrm{x} 3$ = Jigsaw

Populasi pada riset ini terdiri dari semua peserta didik kelas X SMA Negeri 1 Mataram, sejumlah 260 peserta didik yang terbagi ke dalam 7 kelas. Sampel diambil menggunakan teknik cluster random sampling yaitu pengambilan sampel dengan memperhatikan unsur kelas atau kelompok yang terdapat dalam populasi (Riduwan, 2010).

Variabel penelitian yang terlibat terdiri dari variabel bebas, variabel terikat dan variabel kontrol. Variabel bebas dalam penelitian ini yaitu model pembelajaran kooperatif tipe KOSAJI, STAD dan Jigsaw. Variabel terikat yang diteliti adalah hasil belajar kognitif. Variabel kontrol yang dikendalikan dalam penelitian ini yaitu guru yang menyampaikan materi, durasi waktu, konten materi yang disampaikan, waktu penyampaian.

Instrumen yang digunakan dalam penelitian ini meliputi tes untuk mengukur hasil belajar kognitif fisika peserta didik. Instrumen tes yang digunakan terlebih dahulu divalidasi oleh ahli. Setelah itu dilakukan uji validitas, reliabilitas, daya beda dan taraf kesukaran. Semua butir tes yang digunakan dalam penelitian ini telah dinyatakan valid, reliabel, memiliki daya beda soal yang baik dan memiliki taraf kesukaran yang bervariasi dari butir soal yang mudah, sedang dan sulit.

Analisis data menggunakan Anava satu jalur (oneway Anova) dan dilanjutkan dengan uji Tukey HSD pada taraf signifikan 5\%. Analisis diawali dengan uji normalitas dan uji homogenitas.

\section{HASIL DAN PEMBAHASAN}

Data kognitif peserta didik pada mata pelajaran fisika menunjukkan sejauh mana penguasaan peserta didik terhadap konsep suhu, kalor dan perpindahannya. Data pretes pada peserta didik yang belajar dengan model KOSAJI memiliki nilai tertinggi sebesar 67 dan terendah sebesar 37 dengan rerata 50,79. Peserta didik yang belajar dengan model pembelajaran STAD memiliki nilai tertinggi sebesar 66 dan terendah sebesar 23 dengan rerata 44,26 sedangkan pada model pembelajaran Jigsaw memiliki nilai tertinggi sebesar 67 dan terendah sebesar 37 dengan rerata 43,32. Data pretes kognitif fisika peserta didik tersaji pada Tabel 5.

Tabel 5. Data Pretes Kognitif Fisika

\begin{tabular}{|c|c|c|c|c|c|c|}
\hline Model Pembelajaran & Data & $\mathbf{N}$ & Rata-rata & S. Dev & Nilai min & Nilai Max \\
\hline \multirow{2}{*}{ KOSAJI } & Pretes & 39 & 50,79 & 7,70 & 67,00 & 37,00 \\
\hline & Postes & 39 & 87,46 & 3,75 & 93,00 & 73,00 \\
\hline \multirow{2}{*}{ STAD } & Pretes & 39 & 44,26 & 9,18 & 66,00 & 23,00 \\
\hline & Postes & 39 & 74,94 & 6,47 & 90,00 & 60,00 \\
\hline \multirow{2}{*}{ Jigsaw } & Pretes & 38 & 43,32 & 7,32 & 67,00 & 30,00 \\
\hline & Postes & 38 & 74,34 & 6,40 & 90,00 & 67,00 \\
\hline \multicolumn{3}{|c|}{$\begin{array}{l}\text { Data postes pada peserta didik yang belajar } \\
\text { dengan model KOSAJI memiliki nilai tertinggi } \\
\text { sebesar } 93 \text { dan terendah sebesar } 73 \text { dengan }\end{array}$} & \multicolumn{4}{|c|}{$\begin{array}{l}\text { dengan model pembelajaran STAD memiliki } \\
\text { nilai tertinggi sebesar } 90 \text { dan terendah sebesar } \\
60 \text { dengan rerata } 74,94 \text { sedangkan pada model }\end{array}$} \\
\hline
\end{tabular}


pembelajaran Jigsaw memiliki nilai tertinggi sebesar 90 dan terendah sebesar 67 dengan rerata 74,34 . Data selengkapnya dapat dilihat pada Tabel 5. Hasil belajar kognitif peserta didik yang memiliki sikap tinggi terhadap fisika lebih baik daripada peserta didik dengan sikap rendah terhadap fisika. Nilai rata-rata hasil belajar kognitif peserta didik dengan sikap tinggi terhadap fisika sebesar 81,28 (Tabel 5).

Hasil uji normalitas data kognitif fisika peserta didik menggunakan uji chi-square berbantukan program SPSS versi 20 for Windows. Hasil uji chi-square data kognitif fisika peserta didik pada data pretes maupun postes terdistribusi normal $\quad\left(X^{2}\right.$ hitung $<X^{2}$ tabel $)$ seperti yang terangkum pada Tabel 6 berikut.

Tabel 6. Hasil Uji Normalitas Data Kognitif Peserta Didik

\begin{tabular}{ccccc}
\hline Data & $\boldsymbol{X}^{2}$ hitung & Df & $\boldsymbol{X}^{2}$ tabel & Keputusan \\
\hline $\begin{array}{r}\text { Pre- } \\
\text { test }\end{array}$ & 12,09 & 29 & 42,557 & Normal \\
\hline $\begin{array}{c}\text { Post- } \\
\text { test }\end{array}$ & 18,96 & 35 & 49,801 & Normal \\
\hline
\end{tabular}

Hasil uji Levene pada data aspek kognitif pretes maupun postes memiliki nilai sig. $>0.05$ dan Levene statistic < Ftabel, ini artinya data homogen. Lebih jelasnya dapat dilihat pada tabel 7.

Tabel 7. Hasil Uji Homogenitas Data Kognitif Peserta Didik

\begin{tabular}{ccccc}
\hline Data & Fhitung & Ftabel & simpulan & Keputusan \\
\hline $\begin{array}{r}\text { Pre- } \\
\text { test }\end{array}$ & 2,09 & 2,30 & $\begin{array}{c}F_{\text {hitung }}< \\
F_{\text {tabel }}\end{array}$ & Homogen \\
\hline $\begin{array}{r}\text { Post- } \\
\text { test }\end{array}$ & 1,82 & 2,30 & $\begin{array}{c}F_{\text {hitung }}< \\
\mathrm{F}_{\text {tabel }}\end{array}$ & Homogen \\
\hline
\end{tabular}

Hasil uji hipotesis kognitif peserta didik dilakukan dengan analisis statistik Anava satu jalur (oneway Anova) karena memenuhi uji prasyarat (data terdistribusi normal dan memiliki varian yang homogen). Hasil uji hipotesis mengenai pengaruh model pembelajaran pada kognitif fisika peserta didik terlihat pada Tabel 7.

Hasil analisis data kognitif peserta didik menafsirkan ada pengaruh model pembelajaran terhadap kognitif fisika peserta didik $\quad(\mathrm{P}<0,05)$. Nilai $\mathrm{F}$ tabel $(\mathrm{Ft})$ pada taraf signifikan 0,05 dengan derajat kebebasan $(\mathrm{df})=$ (2:110) adalah 3,078 .

Tabel 8. Hasil Uji Hipotesis Kognitif

\begin{tabular}{ccc}
\hline Sumber & $\mathbf{F}_{\mathbf{h}}$ & $\mathbf{P}$ (sig.) \\
\hline Model pembelajaran & 91,989 & 0,000 \\
\hline
\end{tabular}

Hasil penelitian menunjukkan bahwa model pembelakajaran tipe KOSAJI berbeda signifikan dibandingkan dengan model pembelajaran kooperatif tipe STAD dan Jigsaw. Berdasarkan uji lanjut dari ketiga model pembelajaran yang telah diterapkan, model pembelajaran KOSAJI memberikan pengaruh yang paling nyata dibandingkan model pembelajaran kooperatif tipe STAD dan Jigsaw seperti yang ditunjukkan oleh tabel 9 .

Tabel 9. Hasil Uji Tukey HSD

\begin{tabular}{|c|c|c|c|c|}
\hline & \multirow{2}{*}{ Model } & \multirow{2}{*}{$\mathrm{N}$} & \multicolumn{2}{|c|}{ Subset } \\
\hline & & & 1 & 2 \\
\hline \multirow{4}{*}{$\begin{array}{c}\text { Tukey } \\
\text { HSD }\end{array}$} & Jigsaw & 38 & 74.34 & - \\
\hline & STAD & 39 & 74,85 & - \\
\hline & KOSAJI & 39 & - & 87.46 \\
\hline & Sig. & & 0.85 & 1.00 \\
\hline
\end{tabular}

Pada model pembelajaran kooperatif tipe STAD dan Jigsaw menunujukkan tidak ada perbedaan yang signifikan. Temuan ini menafsirkan bahwa penerapan model pembelajaran kooperatif tipe KOSAJI lebih unggul dibandingkan model pembelajaran kooperatif tipe STAD maupun tipe Jigsaw.

Model pembelajaran kooperatif tipe KOSAJI dalam penelitian ini mengitegrasikan langkahlangkah pada model pembelajaran kooperatif tipe STAD dan Jigsaw. Peserta didik dibagi ke dalam kelompok-kelompok kecil agar dapat saling membantu memahami materi pelajaran dan menyelesaikan tugas. Pembelajaran dengan kooperatif tipe KOSAJI memfasilitasi 
peserta didik dalam kelompok belajar secara kolaboratif dengan mengikuti sintaks kombinasi STAD dengan Jigsaw. Para peserta didik yang mengikuti model pembelajaran kooperatif tipe KOSAJI tidak hanya mendapatkan pengetahuan dari presentasi guru di kelas sebagaimana yang ada dalam langkah-langkah pembelajaran kooperatif tipe STAD, namun peserta didik juga mengemban tugas untuk menguasai materi yang dilimpahkan pada saat mereka sebagai anggota kelompok ahli seperti pada model kooperatif tipe Jigsaw.

Setiap peserta didik dituntut untuk menguasai materi tersebut sebelum mereka kembali ke kelompok asal. Setiap peserta didik pun akan mendapatkan pengetahuan dari anggota ahli sehingga pengetahuan yang mereka dapatkan menjadi lebih komprehensif dan kompleks. Melaui integrasi dari kedua model ini, komunikasi dan kerjasama antar peserta didik dalam pembelajaran kooperatif tipe KOSAJI lebih masif dan sering mereka lakukan baik bersama guru maupun antar peserta didik. Secara tidak langsung hal ini berdampak pada aspek kognitif pada mata pelajaran fisika yang mereka peroleh lebih bermakna karena lebih sering diulang dibandingkan hanya menggunakan pembelajaran kooperatif tipe STAD danJigsaw (Rumansyah, dkk., 2016).

Ketiga tipe model pembelajaran ini secara umum membantu peserta didik meraih nilai kognitif pada kategori yang baik. Hal ini membuktikan pembelaran kooperatif tipe apapun baik KOSAJI, STAD dan Jigsaw mampu menggiring peserta didik untuk belajar lebih bermakna dengan mereka belajar bersama. Temuan ini sejalan dengan hasil penelitian yang mengungkapkan pembelajaran kooperatif berkonstribusi dalam meningkatkan hasil belajar peserta didik terutama pada aspek kognitif. Peserta didik terlihat lebih mudah mencerna konsep atau pengetahun ketika ada materi yang susah setelah dijelaskan oleh rekan mereka dalam satu kelompok (Arizona, 2013; Arizona, dkk.,2013; Harjono, dkk. 2015; Qudsy dkk., 2020)). Hal ini senada dengan apa yang diungkapak oleh Slavin (2011) yakni berdasarkan teori, peserta didik akan lebih mudah memahami dan menemukan konsep yang sulit jika mereka mendiskusikan konsep tersebut dengan rekan sebayanya. Pembelajaran kooperatif tidak hanya berimplikasi pada aspek kognitif tersedia bagi semua peserta didik, tetapi juga mengakibatkan proses pemikiran peserta didik lain tersedia bagi setiap orang. Belajar secara kooperatif secara tidak langsung akan memberikan pembelajaran kepada peserta didik melalui cara rekan mereka dalam kelompok berhasil menyelesaikan masalah melalui pendekatan mereka (Slavin, 2011). Hal senada diungkapkan dari hasil penelitian Sudarsana (2018) yang menyatakan bahwa peserta didik yang belajar melalui model pembelajaran kooperatif memiliki nilai rerata hasil belajar yang lebih baik dibandingkan dengan belajar secara konvensional.

Ketepatan dalam memilih memilih suatu model pembelajaran tentunya menjadi suatu keharusan yang dilakukan oleh seorang pendidik sesuai dengan karakteristik materi yang akan disampaikan (Arizona, 2020). Model pembelajaran KOSAJI merupakan salah satu upaya inovasi dari peneliti dalam mengembangkan sintaks pembelajaran (tipe STAD dan Jigsaw). Mencermati upaya reformasi pembelajaran yang sedang dikembangkan di Indonesia, para guru atau calon guru saat ini banyak ditawari dengan aneka pilihan model pembelajaran, yang kadang-kadang untuk kepentingan penelitian (penelitian akademik maupun penelitian tindakan) sangat sulit menermukan sumbersumber literarturnya. Namun, jika para guru (calon guru) telah dapat memahami konsep atau teori dasar pembelajaran yang merujuk pada proses (beserta konsep dan teori) pembelajaran sebagaimana dikemukakan di atas, maka pada dasarnya guru pun dapat secara kreatif mencobakan dan mengembangkan model pembelajaran tersendiri yang khas, sesuai dengan kondisi nyata di tempat kerja masing-masing, sehingga pada gilirannya akan muncul model-model pembelajaran versi guru yang bersangkutan, yang tentunya semakin memperkaya khazanah 
model pembelajaran yang telah ada (Arizona, 2020).

\section{KESIMPULAN}

Berdasarkan hasil penelitian model pembelajaran KOSAJI berpengaruh terhadap hasil belajar kognitif peserta didik. Model pembelajaran kooperatif tipe KOSAJI lebih baik dibandingkan model pembelajaran kooperatif tipe STAD dan Jigsaw. Setiap peserta didik yang mengikuti model pembelajaran ini tidak hanya mendapatkan pengetahuan dari presentasi guru di kelas sebagaimana yang ada dalam sintak pembelajaran kooperatif tipe STAD, namun peserta didik juga mengemban tugas untuk menguasai materi yang dilimpahkan pada saat peserta didik sebagai anggota kelompok ahli sebagaimana pada tipe Jigsaw. Secara tidak langsung hal ini berdampak pada pengetahuan yang mereka peroleh lebih bermakna karena lebih sering diulang dibandingkan hanya menggunakan pembelajaran kooperatif tipe STAD maupun Jigsaw saja. Oleh karena itu model pembelajaran kooperatif tipe KOSAJI dapat dijadikan sebagai salah satu alternatif model pembelajaran untuk meningkatkan hasil belajar kognitif peserta didik khususnya pada pembelajaran fisika.

\section{UCAPAN TERIMAKASIH}

Terimakasih kami ucapkan untuk semua pihak yang telah membantu keberlangsungan penelitian ini, terutama Kepala Sekolah, Para Guru, Karyawan dan Peserta didik-Siswi SMAN 1 Mataram atas arahan, motivasi, kerjasama, dan atensi yang luar biasa.

\section{DAFTAR PUSTAKA}

Anderson, L. W. \& Krathwohl, D. R. (2001). A Taxonomy for Learning, Teaching, and Assessing a Revision of Bloom's Taxonomy of Educational Objectives. New York: Longman, Inc.

Arizona, K. (2020). Inovasi Pembelajaran Fisika di Era Revolusi Industri 4.0. Mataram: Sanabil.
Arizona, K. (2020). Elevating Students'competence Based Ict In The Era Of Industrial Revolution 4.0. Journal of Teaching and Learning Physics, 5(2), 48-59.

https://doi.org/10.15575/jotalp.v5i2.79 87

Arizona, K. Pengaruh Media Tiga Dimensi Kemagnetan Berbasis Inkuiri melalui Strategi Koopertif terhadap Kecakapan Sosial, Sikap Ilmiah dan Hasil Belajar Kognitif Fisika Peserta didik Kelas IX, Tesis S2, Universitas Mataram, 2013.

Arizona, K., Harjono, A. \& Jufri, A.W. (2013). Pengaruh Implementasi Media Tiga Dimensi Kemagnetan Berbasis Inkuiri (MTDKBI) melalui Strategi Kooperatif terhadap Kecakapan Sosial. Jurnal Erudio, 1(2), 134-138.

Daryanto. (2001). Evaluasi Pendidikan. Jakarta: Rineka Cipta.

Eggen, P., dan Kauchak, D. (2012). Strategi dan Model Pembelajaran: Mengajarkan Konten dan Keterampilan Berpikir. Satrio Wahono (Penerjemah). Jakarta: Indeks.

Furchan, A. (1982). Pengantar Penelitian dalam Pendidikan. Surabaya: Usaha Nasional.

Hamalik, 0. (2004). Perencanaan Pengajaran Berdasarkan Pendekatan Sistem. Bumi Aksara: Jakarta.

Harjono, A., Jufri, A.W., \& Arizona, K. (2015). Implementasi Media Tiga Dimensi Kemagnetan Berbasis Inkuiri Melalui Strategi Kooperatif Terhadap Sikap Ilmiah Peserta didik. Jurnal Pendidikan Fisika dan Teknologi, 1(1), 15-23. http://dx.doi.org/10.29303/jpft.v1i1.23 1

Ibrahim, M., Rachmadiati, F., Nur, M. \& Ismono. (2000). Pembelajaran Kooperatif. Pusat Sains dan Matematika Sekolah. Program Pascasarjana UNESA. Surabaya: University Press.

Nur, M., dan Wikandari, P.R. (2000). Pengajaran Berpusat kepada Peserta didik dan Pendekatan Konstruktivis dalam Pengajaran. Pusat Studi Matematika dan IPA Sekolah UNESA. Surabaya: University Press.

Qudsyi, H., Indriaty, L., Herawaty, Y., Khaliq, I., \& Setiawan, J. (2020). Pengaruh metode 
pembelajaran kooperatif (cooperative learning) dan motivasi belajar terhadap prestasi belajar peserta didik SMA. Proyeksi: Jurnal Psikologi, 6(2), 34-49. http://dx.doi.org/10.30659/p.6.2.34-49

Riduwan. 2010. Metode dan Teknik Menyusun Tesis. Jakarta: Alfabeta.

Rumansyah, R., Kosim, K., \& Soeprianto, H. (2016). Pengembangan Model Pembelajaran Kooperatif Tipe Kosaji pada Pembelajaran Fisika. Jurnal Penelitian Pendidikan IPA, 2(2). http://doi.org/10.29303/jppipa.v2i2.42

Rusman. (2011). Model-model Pembelajaran Mengembangkan Profesionalisme Guru. Jakarta: Rajagrafindo Persada.

Sanjaya, W. (2011). Perencanaan dan Desain Sistem Pembelajaran. Jakarta: Kencana Prenada Media Group.

Slameto. (2006). Belajar dan Faktor yang Mempengaruhinya. Jakarta: Rineka Cipta.

Slavin, R. E. (2011). Psikologi Pendidikan Teori dan Praktik Jilid II Edisi Kesembilan. Penerjemah Marianto Samosir. Jakarta: Indeks.

Sudarsana, I. K. (2018). Pengaruh model pembelajaran kooperatif terhadap peningkatan mutu hasil belajar siswa. Jurnal Penjaminan Mutu, 4(1), 20-31.

Sudjana, N. (2012). Penilaian Hasil Proses Belajar Mengajar. Bandung: Rosdakarya.

Sukmadinata, N. S. (2011). Metode Penelitian Pendidikan. Bandung: Remaja Rosdakarya.

Suprijono, A. (2012). Cooperative Learning Teori dan Aplikasi Paikem. Yogyakarta: Pustaka Belajar.

Usman, U. (2005). Menjadi Guru Profesional. Bandung: Rosdakarya. 